Lin, Z. \& Taralynn, H. (2015). Factors Associated with Electronic Portfolio Adoption Among Pre-service Teachers. Journal of Educational Technology Development and Exchange, 8(1), 49-65.

\title{
Factors Associated with Electronic Portfolio Adoption Among Pre-service Teachers
}

\author{
Lin Zhong \\ The University of Southern Mississippi \\ Taralynn Hartsell \\ The University of Southern Mississippi
}

\begin{abstract}
This qualitative study investigates factors that affect pre-service teachers' electronic portfolio adoption process. Data is collected through in-depth interviews and document analysis. Factors affecting pre-service teachers' adoption of electronic portfolio include school requirements, social pressures, time constraints, previous experiences, family consciousness, and personality. Findings suggest that successful electronic portfolio implementation rely on consideration of both external and internal aspects such as time, motivation, interaction, and technological skills.
\end{abstract}

Keywords: Electronic portfolio, pre-service teachers, adoption decisions

\section{Introduction}

Electronic portfolio or ePortfolio is an alternative assessment tool for teaching and learning. The ePortfolio helps display or demonstrate one's learning achievements and outcomes across a set time period. Compared to traditional forms of assessment such as papers, examinations, and projects, ePortfolio represents the learner's achievements that demonstrate what has been learned, gained, acquired, or felt toward a topic area. According to Abrami, Venkatesh, Meyer, and Wade (2013) an electronic portfolio is a: digital container capable of storing visual and auditory content, including text, images, video, and sound. EPs may also be learning tools not only because they organize content but also because they are designed to support a variety of pedagogical processes and assessment purposes. (p. 1189)

They compare ePortfolio as the "knowledge age's version of the artist's portfolio for students in the sense that they not only summarize a student's creative achievements but also illustrate the process of reaching those achievements" (p. 1189). In short, ePortfolio permits a way to measure 
“students' achievements by their ability to create tangible products exemplifying their accomplishments in terms of analysis, synthesis, and evaluation" (Smaldino, Russell, Heinich, \& Molenda, 2005, p.14). Teachers frustrated with more conventional assessment methods have turned toward electronic portfolios to evaluate learning as "a truer, more rounded view of an individual's strengths and weaknesses" (Smaldino, Russell, Heinich, \& Molenda, 2005, p.14).

\section{Literature Review}

ePorfolio has been widely used in online education as a learning enhancement tool to store and showcase individual achievement for almost two decades (Girish, Issack, \& Ravindra, 2011). ePotfolio is also used as a self-assessment tool for the professional development of pre-service and in-service teachers in different content areas (Masari, 2013). Further, as a self-assessment tool for learning, ePortfolio serves as a foundation for documenting the acquisition of skills and knowledge over time (Huang, Yang, \& Chang, 2011).

Teacher education programs have adopted ePortfolio, which is used in managing, assessing, and demonstrating learning of teacher education candidates (Fan \& Reynolds, 2014; Firdyiwek \& Scida, 2014; Roberts, 2014; Silva, Larsen, Park, \& Tai, 2015; Tur \& Urbina, 2014). A survey conducted by the Annual Association for Authentic Experiential Evidence-Based Learning shows that $50 \%$ of educational departments in the United States and 400 colleges have provided financial support for programs relating to the development of ePortfolio in teacher education programs (Britten, Mullen, \& Stuve, 2003). ePortfolio has been demonstrated as an effective tool in pre-service teacher education and for the continued professional development beyond the university classroom (Boulton, 2014; Buyarski \& Landis, 2014; Carson, McClam, Frank, \& Hannum, 2014).

However, discontinuance of using ePortfolio has been reported (Ritzhaupt, Ndoye, \& Parker, 2009). Gardner and Aleksejuniene (2008) reported that some universities discontinued ePortfolio because ePortfolio was time-consuming to develop and manage. Shepherd and Bolliger (2014) explained that students immediately discontinued using ePortfolio because they were not interested in updating and maintaining their ePortfolios finishing the class or graduated from the program. Ritzhaupt, Ndoye, and Parker (2009) investigated teachers' perspectives toward the functionality of ePortfolio and more than $70 \%$ of teachers reported the ePortfolio being less useful in their professional tasks such as lesson planning. More than $90 \%$ participants in the study informed that they would not continue updating and maintaining the ePortfolio in their future careers.

Reasons for discontinuance of ePortfolio usage were various. Gaitán (2012) pointed out that the clarity of purpose, institutionally or individually, was essential in driving ePortfolio usage. Van Wesel and Prop (2008) found the key factors of successful ePortofolio implementation were self-reflection skills and computer skills. Wuetherick and Dickinson (2015) investigated students' perceptions of ePortfolio use in continuing education environments and results showed that experience and comfort levels with technologies were keys to ePortfolio adoption and continuous implementation. Boulton (2014) investigated whether ePortfolio could continue to support pre-service teachers' professional development during teaching careers. Results showed that functional use of ePortfolio was quite limited in schools because the link to pre-service teachers' professional 
development was not embedded into teachers' education. Hsieh, Chen, and Hung (2015) conducted longitudinal tests of ePortfolio use over time. Results demonstrated that ease of use, attribution, satisfaction, and expectations were keys factors influencing continuous use of ePortfolio. However, Hsieh, Chen, and Hung's (2015) study only focused on the adoption and continuous stages of ePorfolio within context of teachers' education. Discontinuous use of ePortfolio could occur in other stages such as implementation and confirmation (Bolliger \& Shepherd, 2010).

To gain a deeper understanding of factors that influence the motivation concerning continual usage of the ePortfolio in teacher education programs, this paper explores preservice teachers' experiences of ePortfolio based on Rogers' (Rogers, 2003) diffusion of innovations theory. Specifically, this study investigates (a) how information and exposure to the innovation (ePortfolio) is more likely to give rise to ePortfolio adoption, (b) how individuals may have been persuaded to adopt ePortfolio, (c) factors that may influence individuals' decision of adopting ePortfolio, (d) how individuals experience ePortfolio implementation, and (e) how individuals confirmed their ePortfolio implementation and adoption for future use. The following research questions have been developed to guide the research design and data collection process:

1) How has ePortfolio been exposed to preservice teachers?

2) How have pre-service teachers been persuaded to adopt ePortfolio?

3) What factors have affected pre-service teachers' decision to adopt ePortfolio?

4) What do pre-service teachers experience during ePortfolio implementation?
5) What types of pre-service teachers have confirmed ePortfolio adoption?

\section{Theoretical Framework}

This study is based on Rogers' diffusion of innovations theory (Rogers, 2003). Innovation diffusion theory provides a model of the innovation-decision process that consists of five-stages: (1) knowledge stage, (2) persuasion stage, (3) decision stage, (4) implementation stage, and (5) confirmation stage. The innovation-decision process begins with the knowledge stage as a person is exposed to basic knowledge and understanding of the innovation is formed. The person then decides to adopt or reject the innovation in the decision stage that may lead to the implementation stage depending upon the decision. After implementation, the person supports the decision in the final confirmation stage. Individuals' decisions to accept the innovation during the five-stage could affect the rate of innovation adoption (Rogers, 2013).

Relative advantages, compatibility, complexity, trialability, and observability are considered as the main factors that affect innovation diffusion (Rogers, 2003). Preservice teachers first compare the advantages of ePortfolio with previous assessment tools during the knowledge stage. They also think about the compatibility of ePortfolio with current course or program requirements before they decide to adopt ePortfolio. For example, most teacher education programs require pre-service teachers to develop ePortfolio as program assessment tool. Thus, more than $90 \%$ of pre-service teachers tend to adopt ePortfolio due to these external motivators. If the process and tools of developing ePortfolio are not complex, more pre-service teachers will adopted it. Once pre-service teachers get the chance of testing and observing ePortfolio to experience the advantages of ePortfolio, 
they are more likely to adopt ePortfolio. Therefore, examining the ePortfolio diffusion process can help researchers discover how pre-service teachers' decisions are affected by the factors categorized above.

\section{Methodology}

This qualitative study examines reasons why pre-service teacher education students may or may not adopt ePortfolio in their academic programs. Foundation for developing the research questions to guide the study came from Rogers' five-stage innovation of diffusion theory. The researchers assume that as individuals are exposed to ePortfolio in their teacher education programs, they are more likely to adopt this assessment tool in their own classrooms.

Qualitative research methods are used in this research design to help the researchers obtain a thorough understanding of the experiences and thought processes behind the pre-service teacher education students. Interviews and document analysis are the primary instruments of data collection for examining ePortfolio adoption.

\subsection{Setting}

The research setting was pre-service teacher education programs focused on elementary education and special education licensures at a southern university in Mississippi. ePortfolios, which is embedded into TK20, is one of the continuous enrollment requirements for pre-service teachers. TK20 is an assessment system that provides ePortfolio for pre-service teachers to store, track, and retrieve data for educational proposes. Preservice teachers need to subscribe TK20 and upload their artifacts of ePortfolio in TK20. Pre-service teachers can start to work on ePortfolio as early as they enroll the programs and can revise the artifacts included in ePortfolio whenever they want.

In this study, the participants were recruited from the students enrolled in a Computer Applications in Education course, which is a required course for pre-service teachers. The course is an undergraduate level course that requires students to complete an ePortfolio as the final project to document students' achievement in this class. Participants were recruited from this course because this required course is an important source for pre-service teachers to get knowledge of ePortfolio. Students from this course can provide rich information of ePortfolio that helps the researcher get deeper understanding of ePortfolio implementation. This course is taken during the first-year in the teacher education block and is the only technology-related course for the program. The course covers different topics such as technology applications, software programs, Web tools, online learning, ethical practices, and more. One requirement for students in the course is to create a blogfolio or ePortfolio as their final projects. The ePortfolio is created using blogging software (e.g., Blogger, Wordpress). Throughout the course, students type self-reflections concerning each assignment or artifact, and create a hyperlink to that assignment or artifact. An introduction and final course reflection are also included on the ePortfolio. Reflections discuss students' learning experiences, problems or issues they encountered, how they could use the software or technology tool in their teaching, and future learning goals. Further, they have to comment on how completing the particular assignment helps them achieve ISTE's technology standards for teachers (http://www.iste.org). The final ePortfolio includes nine to ten reflections with hyperlinks, images, videos, etc.

The purpose of the ePortfolio is to 
demonstrate student learning and thoughts toward practical application of the technology tools covered in the course and future classroom activities. At the end of the term, students share their ePortfolios with others in class and comment upon them. The ePortfolio serves as a compilation of learning that has occurred. Although not all of the participants' experience of creating ePortfolio is solely localized in this particular class, as one will read later, this course has been a first-time exposure to some of the participants.

\subsection{Participants}

The participants in this study include nine pre-service teachers enrolled in Computer Applications in Education course. Except one participant who is forty-six old, the rest of the participants are regular college age between 21 and 25. All participants are full-time students from different teacher education programs in the department at the university (e.g., elementary, special education). Besides the one male student, the remaining participants are female. An oral recruitment announcement was made during the final class meeting after grades were calculated. The announcement asked for participation among the students taking the course. The decision to make this announcement so late in the semester is so that students would not worry about their grades being affected by their participation or nonparticipation. Choosing students from Computer Applications in Education is a good sample because students in this class have gained experience of ePortfolio, whether prior experience existed or not. Some students in the course even adopted ePortfolio as a form of learning tool after this class. The students or participants from this course can provide rich information of the ePortfolio adoption process for this study.

For the purpose of privacy protection and anonymity and confidentiality, pseudonyms are used throughout the data collection process whenever possible, with all transcripts ascribed to the pseudonyms. All names used in this study are fictional. Demographic information for the participants is summarized in Table 1.

Table 1. Pre-service teachers demographic information

\begin{tabular}{lllll}
\hline Names & Gender & Age & Level & Program \\
\hline Alice & F & 21 & Senior & Elementary Education \\
Rebecca & F & 46 & Senior & Elementary Education \\
Tammy & F & 23 & Sophomore & Special Education \\
Jessica & F & 22 & Junior & Special Education \\
Leo & M & 21 & Senior & Elementary Education \\
Andrea & F & 22 & Senior & Special Education \\
Holly & F & 25 & Junior & Elementary Education \\
Linda & F & 24 & Junior & Elementary Education \\
Mary & F & 21 & Senior & Elementary Education \\
\hline
\end{tabular}

\subsection{Data Collection and Analysis}

An exploratory case study is selected in this study to explore real-life experiences through detailed and in-depth data collection 
involving interviews. Qualitative research methodology using interviews is especially well-suited for this study to explore and understand the complex decision process within a unique context because of its ability to support a rich description of the ePortfolio adoption process (Yin, 2013).

According to Yin (2014), using multiple sources of qualitative data helps construct reliability and validity of the study. Therefore, besides collecting data through interviews, documents from teachers programs are also included and analyzed. Thus, two types of data are collected and analyzed: (1) in-depth interview and (2) document analysis.

Face-to-face, in-depth interviews are the primarily research instrument to gather information. An interview protocol has been developed using the research questions as the focus. Because the purpose of the interview is to examine pre-service teachers' adoption decision of ePortfolios, the interview protocol asked questions concerning the five-stages of the innovation decision process. Participants are interviewed with a list of nine openended interview questions concentrated on understanding the ePortfolio adoption process. Interviews are conducted face-to-face and audio recorded after participants have signed the consent form. Interviews occurred one session per participant and lasted for less than an hour.

Documents, including participants' online ePortfolios and programs' study plans, have been collected and analyzed. Participants' online ePortfolio demonstrate and support participants' thoughts regarding the reasons of adopting ePortfolio. Study plans help the researchers locate potential external factors that could affect pre-service teachers' adoption decisions.

After data collection, interviews and document notes have been transcribed into word processing files for analysis. Researchers read through all the data and wrote memos to gain a general understanding of the data. This process was repeated four times to generate themes and patterns for organizing the findings. Results were organized around the research questions and discussed in the following section.

\section{Findings}

The study provides some interesting findings based upon the pre-service teacher education students' experiences concerning ePortfolio. As part of the course project in the Computer Applications in Education course, students have been exposed to ePortfolio development. The findings include the most relevant statements taken from the interviews and the presentation of the documents (ePortfolio) completed by the participants. These findings are organized into the five research questions for better understanding.

\subsection{How has ePortfolio been exposed to pre- service teachers?}

In the knowledge stage of Rogers' (2003) innovation diffusion model, students were exposed to or introduced to ePortfolio initially that could affect later adoption. Actually, four ePortfolio adopters, including Alice, Jessica, Leo, and Rebecca, said they had to complete an ePortfoilio in other courses in the teacher education program. In other words, their professors were the main knowledge source of ePortfolio instruction. Students said they trusted their instructors and found the knowledge regarding ePortfolio reliable in helping them understand ePortfolio and how it worked. Tammy reported she became aware of ePortfolio by researching the Internet. Rebecca stated that she was aware of ePortfolio not just from her professor, but also from her friends 
and colleagues in the program.

The ePortfolio knowledge-gaining channels were from class learning, Internet, and friends. In class, the instructor is the primary knowledge source. Students trusted their instructor and thought information that the instructor delivered was reliable. Online articles and YouTube also helped students obtain more ePortfolio knowledge based on personal needs. Regardless, initial exposure to ePortfolio was present in the teacher education program and used as a form of learning assessment either for individual classes or for the unit.

\subsection{How have pre-service teachers been persuaded to adopt ePortfolio?}

After individuals were exposed to ePortfolio, they formed their own attitudes toward ePortfolio. Participants reported their experiences related to the persuasion stage including: who helped their decision process, the reasons behind the decision, other information seeking activities, and the places they tried and observed ePortfolio development and implementation. Everyone showed positive attitudes toward ePortfolio as a learning and assessment tool, even though they reported different reasons for using it. Tammy said, "I found it nice because I could have copies of my work located everywhere." ePortfolio was considered as an electronic archive, online archive, and reflective tool for the adopters even though they were required to use or adopt ePortfolio in the course.

Class requirement was the main reason for adopting ePortfolio because students found personal motivation, rather than general advantages, of creating the ePortfolios. Andrea said, "ePortfolio was introduced by one of my instructors. It was my first time to know ePortfolio. We were required to create an
ePortfolio in that class. The instructor presents ePortfolio very positively and she says this is a tool that we will use in the future. I think it is very useful."

Personal need was another reason of choosing ePortfolio because of its convenience of not being limited by time and place. Mary said, "My friends asked me try this. So I need to have one to connect with my friends, family, and colleagues. It is very convenience and easy to navigate."

\subsection{What have affected pre-service teachers' decision to adopt ePortfolio?}

When individuals formed their attitudes towards ePortfolio and participated in ePortfolio development, they made the decision to adopt ePortfolio or reject ePortfolio. In this study, all participants chose to adopt it because they found ePortfolio useful, convenient, and helpful. Factors such as social pressure, course requirements, and individual needs influenced their decisions. Rebecca mentioned social pressure being placed on her for developing ePortfolios. This was an interesting finding considering that the literature did not discuss this factor.

Course requirements regarding ePortfolio were reported by three interviewees as influencing their choice to use the medium. Individual or personal needs also influenced individuals' decision to adopt ePortfolios as Tammy reported:

When I was seeking ePortfolio information from the Internet, I saw some teachers' ePortfolio and also my friends showed me their art ePortfolio. So, I wanted to have my own electronic art portfolio. I have an art paper-based portfolio already. I was wondering how to transform my paper portfolio to ePortfolio. Besides, I want to have electronic copies so that I could view my work 
anytime and anywhere I want.

According to Rogers (2003), there are five adopter categories: (1) innovators who are the first ones to adopt the new innovation; (2) early adopters are those who accept the innovation earlier than the majority, but later than the innovators; (3) early majority is the first sizable unit of innovation adopters; (4) late majority are those who accept the innovation behind the early majority; and (5) laggards who are the last ones to accept the innovation. Three participants (Jessica, Tammy, and Leo) fell into the late adopter category. Factors affected their placement included age, prior experience, and peers' influence. The remaining two participants (Rebecca \& Alice) were early adopters. Reasons included course requirement and prior experience. The participants in this study came from a range of adopter categories for various reasons.

\subsection{What do pre-service teachers experience during ePortfolio implementation?}

When individuals put ePortfolio into practice, a lot of expected and unexpected issues occurs that could impact ePortfolio implementation. As Rogers (2003) mentioned, implementation needs overall change, including mental and physical activities. A certain amount of uncertainties could happen during this process. In this study, time was the unexpected primary issue and had been reported by two participants (Alice \& Jessica). Alice said, "If I have more time, I can do better. It's good idea but this semester is just crazy. We have so much work to do. I am not allowed to work on it too long." Besides time, two participants (Leo \& Tammy) reported technical difficulties encountered during the implementation stage. Another issue reported by Rebecca was very interesting. She said:
The amount of information I put out there is because I am aware of that. You know, once it's out there, it stays out there no matter how hard you try to delete. So, you really have to make good choices before you post something and that's the disadvantage because most people just do it and think later what they've done. And, then I have to be very conscious of the effects because I have children.

Overall, in the implementation process, time and technical issues were the main factors that caused ePortfolio adoption to either falter or be discontinued. Because of time and technology limitations, students were not able to spend too much time on the ePortfolio project that was required in class. However, if more time was given, students said they could do better. Therefore, the goal of ePortfolio learning in class needs to concentrate on delivering a thorough and very detailed process of ePortfolio development. This can help students learn how to become familiar with the technology necessary for future ePortfolio development, maintenance, and updates.

\subsection{What types of pre-service teachers have confirmed ePortfolio adoption?}

According to Rogers (2003), confirmation is a process of seeking reinforcement for the innovation decision that has been made earlier. In other words, confirmation is to check whether individuals integrate the innovation into their ongoing routines. The confirmation stage includes the individual recognizing the benefits of using the innovation and promoting the innovation to others.

In this study, all participants except for Leo reported no confirmation in this study. Rest of the participants did not report any confirmation activities when they finished their ePortfolio development. They said time 
was the main reason they did not confirm their work or go back to make changes and updates.

All participants, except for Leo and Jessica, reported discontinuous use of ePortfolio in this study. Alice and Tammy gave up the use of ePortfolio because of their tight time schedules. Rebecca discontinued using ePortfolio because she worried about the effects on her kids. On the other hand, Leo and Jessica continued to use ePortfolio for their personal and professional goals. Leo kept using ePortfolio because he thought ePortfolio was convenient for him and useful for his future teaching. Jessica mentioned in her reflections that ePortfolio was very beneficial in documenting the learning and teaching processes. The artifacts included in the ePortfolio demonstrated students' skills.

Overall, a few students confirmed their decisions in this study to continue using ePortfolio as a teaching, learning, and assessment tool. The ones who rejected the innovation or ePortfolio did so because of limited time. In other words, time was the primary factor that impacted students' confirmation process. Although some students went back and checked their ePortfolios, they only checked the technology functions of the ePortfolio rather than checking and reinforcing their innovation decision.

\section{Conclusions and Discussion}

This study explores factors affecting the electronic portfolio adoption process among pre-service teachers within Rogers' (2003) innovation diffusion theoretical framework. Nine pre-service teachers who use ePortfolio participated in this research, although not all are continuing its use. An open-ended interview protocol has been developed and chosen as the instrument to collect data. Results show that school requirements, social pressure, time, previous experience, impact on family members, and personality are the primary factors that influence ePortfolio adoption in this study.

\subsection{School Learning}

School learning is the main ePortfolio diffusion channel. Most students know about ePortfolio from school. Although they are required to create their own ePortfolio in class, most of them show positive attitudes toward ePortfolio and find it useful for their future teaching. Some participants have had previous background in portfolio development, while others do not. This difference is evident when interviewing the pre-service teacher education students as they discuss problematic issues surrounding ePortfolio adoption (e.g., technology skills, format and design). Because ePortfolio is most effectively delivered online as opposed to a jump drive or CD-ROM, the Internet is a good source of creating ePortfolios. Students who already have portfolio or ePortfolio experience seem to have an easier time in creating their learning portfolio compared to students without ePortfolio experience. They know what is needed in the ePortfolio in terms of content and what they have to do to ensure that the ePortfolio is effective.

When teaching ePortfolio development to pre-service teacher education students, tasks related to ePortfolio should be designed for different purposes. For students with experience, instruction should be more purposeful or targeted to concentrate on how to make the presentation of content meaningful and using various tools to make the ePortfolio more appealing. For students without experience, tasks can be more general and focus on helping students understand the basics of ePortfolio and become more aware of its functions. School requirements 
concerning the use of ePortfolio in this study affects the knowledge and persuasion stages in the diffusion process by requiring pre-service teachers to develop their own ePortfolios. In this process, pre-service teachers adopted ePortfolio because they found the advantages of ePortfolio after they were exposed to the knowledge of ePortfolio.

\subsection{Social Pressure}

Social pressure is an interesting discovery that the literatures do not mention. Pressures from friends, colleagues, and family play an important role in the decision-making process and even speed-up the adoption decision. In this case, Rebecca was persuaded by her family and friends to adopt ePortfolio before she found advantages of ePortfolio. She improved her knowledge of ePortfolio by sharing information with friends, colleagues, and family. She learned new knowledge under pressure from her friends and family. According to Rogers (2003), adopters may be inclined toward using an innovation by the collective. In this case, social pressure is tied more toward the late majority or the group that adopts new ideas after the average member of a social system. They are more cautious and reluctant to adopt until most others do first. Although they may be have been persuaded about the functionality of an innovation, strong pressure from peers is needed to get this group to make to the move.

This factor mainly impacted the knowledge and persuasion stages. Pre-service teachers were forced to expose to ePortfolio because of social pressure from their friends and classmates. As a result, they were persuaded to adopt ePortfolio in the decision and implementation stages. Social pressure provides an opportunity of experiencing ePortfolio and those experiences make students accept ePortfolio as a useful tool for their learning and future teaching.

Taking social pressure into consideration, teaching ePortfolio development in teacher education should begin early. Because the late majority or laggards tend to wait until everyone else uses the ePortfolio, beginning early in the teacher education program can help establish a group of early adopters. The early adopters can then communicate the importance of ePortfolios as a teaching and learning tool to others in the program. As a result, by the time most students reach toward the end of the program, everyone can be at the same level of ePortfolio adoption and have the experience and knowledge of its functionality.

\subsection{Family and Safety Consciousness}

Increasing family consciousness are unexpected results in this study, which is also very interesting. For the purpose of protecting family members, more and more people are very conscious about the information they put online. For example, artifacts included in the ePortfolio may not be appropriate for other family or kids to view, or the ePortfolio developer wants to keep their work private. Although most ePortfolio is password protected, the medium is still likely to expose personal and private information accidently. This factor raises students' concerns regarding the information they put online and usually affects the persuasion and confirmation stages. Because of untrusted information protection methods, pre-service teachers do not want to put their personal information and artifacts online. They worry about how the information in their ePortfolios might impact their family members especially kids. They have to think it over before they post something in their ePortfolios.

Although not directly tied to family, there 
is a consciousness of Internet safety (Smaldino, Russell, Heinich, \& Molenda, 2005). As future teachers, the students are aware of the ethical issues of posting materials online. For instance, posting private information such as names, addresses, phone numbers, etc. is a concern, as most portfolios require some kind of resume or personal contact information. Also, posting pictures of students online, especially minors, is another area of concern even though the pictures can help explain the content of the ePortfolio. As a teacher, this is an issue to be dealt with. Other concerns include posting copyrighted material online. Although Fair Use Guidelines may help teachers and students a little bit in this regard, copyright violations can still exist. Finally, issues surrounding intellectual property or avoiding others from copying their works, ideas, etc. from their ePortfolios can become problematic.

Family and safety consciousness affected the confirmation stage. When pre-service teachers tried to seek further information that reinforced their adoptions, family and safety concerns rose and discontinuance was very possible to occur. Disenchantment discontinuance, which was one type of discontinuance, could appear. Family and safety consciousness causes pre-service teachers to feel ePortfolio as inappropriate for them. Therefore, some pre-service teachers rejected ePortfolio even they had adopted it earlier.

An implication for teaching portfolios is to provide thorough explanation and examples of proper uses of online content. A review of legal and ethical concerns surrounding ePortfolio design should be covered early in the teacher education program. This instruction should be reinforced throughout the program as teacher education students enter real classrooms. Consequences, good or bad, should be demonstrated to help students learn about proper procedures of creating ePortfolios. Therefore, they need more time to work on their ePortfolios to be sure that all areas are covered.

\subsection{Time}

Time is the major factor that influences ePortfolio adoption process as demonstrated by other researchers (Shepherd \& Bolliger, 2014). Time has great impact on the implementation stage of the innovation decision process. Because ePortfolio is timeconsuming, students are not able to spend much time on development. Therefore, time affects the quality of ePortfolio and slows down the implementation stage. In addition, ePortfolio update and maintenance require a lot of time. This explains the discontinuance after pre-service teachers graduate from teacher education program (Ritzhaupt, Ndoye, $\&$ Parker, 2009). Documenting and organizing artifacts are time-consuming for pre-service teachers as they develop ePortfolios for individual courses and as an assessment portfolio for the teacher education program upon graduation. However, as more emerging technologies enter the classroom, pre-service teachers need to learn new technology tools if they are to effectively teach students (Smaldino, Russell, Heinich, \& Molenda, 2005). Teachers who do not have rich experience of technologies have to spend hours or even days on new technology learning. Because ePortfolio uses online technologies, hardware, and software programs to develop the content, creating ePortfolios can help preservice teachers acquire technology skills and knowledge. In addition, such knowledge can assist them, as teachers, using ePortfolios as assessment tools for their own students. With the experience gained, pre-service teachers may encourage ePortfolio development among their own students in the classroom. 
An implication of this issue is permitting students more time to develop the ePortfolio across the course and/or program. Teaching the ePortfolio in segments or chunks might help students manage time themselves. Also, allowing students to work on the portfolios during class time, instead of outside class time, can encourage students to do a better job in designing and maintaining their ePortfolios during the implementation and confirmation stages. In short, permitting more time to work on the ePortfolio may motivate students to adopt the innovation and continue using it in their future.

\subsection{Personality}

Personality is also an interesting finding in this research. Two participants reported internal reasons of being late adopters. This study showed internal factors such as personality and habits also impacting people's decisions, especially adoption speed. For instance, individual openness to technology, patience with technology, technology selfefficacy, and attitude toward technology may affect the innovation adoption. Personality affected the knowledge and persuasion stages. One participant said she was a detailed person and she always looked for more information before she decided to accept something. Compared with regular adopters, this participant needed more time in knowledge and persuasion stages. Another participant reported she did not grow up with technology and did not have enough patience with technology. She became easily angry when she could not get through the technology. Thus, careful design of the innovation diffusion length is needed because some people are cautious and they always need more time to confirm their decisions.

Instructional implication concerning this area is for the instructor to examine student learning characteristics and background. Discovering what background students have with ePortfolio and what attitudes/perceptions they possess can help the instructor target areas that need more demonstration and explanation. Instructors could find ways to present ePortfolio to meet the needs of the students and match their personal and academic motivations. Without an understanding of the learner characteristics, teaching content can be difficult. If students find value and benefits in developing ePortfolio for their professional careers, they may be more likely to sustain or confirm ePortfolio in their future teaching.

\subsection{Technology Skills}

The biggest issue during ePortfolio development process is the lack of technology skills, which usually happens during the implementation stage. Development tools are not an issue any more because of the variety of choices. However, image size becomes an issue. Students lack skills of picture editing, and therefore, they need to spend a lot of time on learning image editing skills. This issue usually causes discontinuous use during the decision process. One participant reflected that the least favorite part of ePortfolio was the images. She had to spend a long time on the images compared with other parts of ePortfolio. Making the image smaller was one of the challenges reported by the participants. In addition, exporting images from phones to the computers became another challenge. Most participants use their phones to take pictures. However, they have difficulties to export the pictures from the phones to the computers before they work on the pictures. Another issue concerning technology is ePortfolio settings, including the layout, theme, blogroll, and other system settings. Most participants said they were frustrated with the ePortfolio settings at the beginning and even wanted to give up. Lacking enough technology skills 
impacted ePortfolio implementation stage. Pre-service teachers are more likely to reject ePortfolio during the implementation stage. No matter what development tool pre-service teachers choose to create their ePortfolios, they need to clean up the ePortfolio layout first and then add necessary modules and information. Most pre-service teachers lack those basic technology skills to be ready for ePortfolio diffusion.

When teaching ePortfolio to teacher education students, focus should be on the technology tools. There are instances when instructors in teacher education programs assume that students know how to use technology and what is needed to create the ePortfolio. For instance, instructors have often given the criteria of what needs to be included in the ePorfolio, but then leave it to students to select which tools to use. As a result, students have unequal access and adequate technology skills in creating an ePortfolio (Smaldino, Russell, Heinich, \& Molenda, 2005). Better for instructors is to specify which hardware and software to use and then actually demonstrate that hardware and software. This way, all students will be on the same level of technology access and skills. They can also help each other when problems arise and not contact the instructor all the time. This can help improve the quality of the ePortfolio and encourage the adoption process.

\subsection{Interactions}

Each factor described earlier influences and interacts with other factors. Interactions among the factors should not be ignored when teaching and using ePortfolio in teacher education programs. For instance, school requirement and previous experience affect the time that students need to finish their ePortfolios. Students with prior experience are faster than students who know nothing about
ePortfolio, making the situation less stressful. As a result, the quality of ePortfolio drops when the due date is closing. Personality and attitude toward ePortfolio affects the quality of ePortfolio also. Some students may be perfectionists, taking more time toward designing and fulfilling the requirements of the ePortfolio, while others will wait till the last minute. Again, this can influence the quality of the ePortfolios meeting academic standards of the teacher education program.

Interaction also affects ePortfolio adoption process and should be considered in the instructional design process. Focus of ePortfolio research should move away from demonstrating the benefits and more toward the implementation decision. More attention should be paid on impacting factors and issues during the technology diffusion process. Results from this study indicate that both external and internal factors and their interactions influence ePortfolio adoption process. The instructor should pay attention to social pressure and increasing family consciousness when considering ePortfolio use in teaching and learning. A good strategy, such as asking students to share their ideas and ePortfolio work with their friends and family, can be utilized by instructors. In addition, shortening the length of developing the ePortfolio process can also help students adopt ePortfolio easier and faster.

Discontinuance, an issue reported in this study, should be given special attention. Discontinuance is very common in regards to technology adoption and not just in ePortfolio diffusion (Shepherd \& Bolliger, 2014). People may accept the technology, but do not continue using it for some reason. They forget how to use the technology innovation after a period of time. In addition, some functions of the technology do not work because of system updates. This implies that instructors should 
decrease or avoid discontinuous use when designing the technology and/or activity. The goal of ePortfolio is not only to introduce the technology that is appropriate for teaching and learning but also to utilize the assessment tool in teaching and learning. Solving discontinuance of ePortfolio improves the quality and quantity of technology diffusion for assessing learning outcomes in teacher education programs (Boulton, 2014).

\section{Recommendations}

ePortfolios can have positive results if implemented properly. If pre-service teacher education students have pleasant experiences when developing ePortfolios, they are more likely to adopt them for future use. Further, if students are required to use ePortfolios more than once, adoption is more likely to occur. Several steps could be taken to ensure positive results.

- Reinforcement - If ePortfolio is being used in one course, this requirement should also be used in other courses to continue the learning and reinforce its importance. If ePortfolio is a one-time requirement, students are more likely to forget its application. In addition, requiring ePortfolio development across courses in a program allows students to experience different formats and expectations. For instance, an ePortfolio in a math methods course may be different from a literacy course in education. Varying the experience can help strengthen ePortfolio's advantages among future adopters.

- Practical discussions - Students need to see value in the requirements they complete for their academic programs. As part of students completing ePortfolios, discussions need to be held that highlight their practicality in real-life settings, especially in the classroom. Without actual classroom experience, students have a difficult time relating ePortfolios with curriculum planning, learning activities, and assessment. A discussion of how each aspect of an ePortfolio can tie to curriculum is useful. For instance, introducing ways that ePortfolio can accommodate different learners, help students achieve academic standards, relate ePortfolios to learning objectives and assessment measures, etc. can assist in providing practical aspects for future classroom teachers.

- $\quad$ Role model - Instructors should model ePortfolio use themselves. If students see that instructors are using ePortfolios, most likely for professional development, this can stimulate motivation of students to adopt this method of learning assessment. Further, ePortfolios created by instructors can serve as examples for students to view. Instructors sharing their own experiences in developing ePortfolios for different purposes can stimulate interest among students as they learn what to do and not to do.

- Emphasis on future use - Instructors should emphasize the advantages of ePortfolio not only for their courses and programs, but also for their future careers. First, explain how the ePortfolios could be used for job interviews that showcase skills and knowledge that have been gained. Personal interviews cannot cover everything that a student may know concerning a topic or skill, and most employers will want "evidence" that the student can perform the task. Second, because ePortfolios are created with different forms of technology and most likely displayed online, instructors should 
emphasize to students the need to update ePortfolios. An employer may search online concerning a particular student and come across his or her ePortfolio. If the student has not updated or made improvements to the content, then this may hold against the student getting a job as the employer sees him or her as being negligent.

In order for ePortfolio adoption to take place, students need to understand the benefits of integrating this medium into their teaching and learning. This study has identified some ways that instructors could introduce and support ePortfolios as a part of the learning process. The bottom line for sustaining ePortfolio use is through the reinforcement of its practicality, the application to assess learning, to help showcase learning that has occurred, and its accessibility to share with others.

\section{Future Research}

Because of limited time, only interview data and individual ePortfolios were included in this study among the nice pre-service teacher education students. This small sample cannot be generalized to the larger population of ePortfolio adopters. However, the findings did show some critical and relevant issues concerning the adoption of ePortfolios.

To better demonstrate validation and reliability of the research results in the future, more data sources such as observations and document analyses should be applied with students from different majors, courses, teacher education programs, etc. during the implementation of ePortfolios. Observing teacher education students, while either learning about or teaching ePortfolios to others, could help identify critical sources to consider when the decision to implement
ePortfolios is made in schools or programs.

Demographics should also be taken into consideration such as gender, ethnicity, education level, majors, learning style, etc. For instance, only one male pre-service teacher education student participated in this study. Factors that might influence ePortfolio adoption could be different between gender and other demographic factors. Studying user or adopter demographics may be beneficial for addressing ePortfolio adoption.

Further, quantitative research methods such as descriptive and experimental could be useful in identifying different variables that affect adoption of ePortfolios. Quantitative measures could reach a larger population to find more generalizable factors involving the adoption of ePortfolios, as opposed to qualitative. In addition, experimental studies may help examine strategies for assisting the adoption process of ePortfolios, thus eradicating the issue of discontinuance. 


\section{References}

Abrami, P. C., Venkatesh, V., Meyer, E. J., \& Wade, C. A. (2013). Using electronic portfolios to foster literacy and selfregulated learning skills in elementary students. Journal of Educational Psychology, 105(4), 1188-1209.

Britten, J., Mullen, L., \& Stuve, M. (2003). Program reflections on the role of longitudinal digital portfolios in the development of technology competence. The Teacher Educator, 39(2), 79-94.

Bolliger, D., \& Shepherd, C. (2010). Student perceptions of ePortfolio integration in online courses. Distance Education, 31(1), 295-314.

Boulton, H (2014). ePortfolios beyond preservice teacher education: A new dawn? European Journal of Teacher Education, 37(3), 374-389.

Buyarski, C. A. \& Landis, C. A. (2014) Using an ePortfolio to assess the outcomes of a first-year seminar: Student narrative and authentic assessment. International Journal of ePortfolio, 4(1), 49-60.

Carson, A. S., McClam, S., Frank, J., \& Hannum, G. G. (2014). ePortfolio as a catalyst for change in teaching: An autoethnographic examination of transformation. International Journal of ePortfolio, 4(1), 73-83.

Fan, S., \& Reynolds, B. (2014). E-Portfolio: A useful tool for early childhood teacher education. 11th International Conference on Excellence in Education: The Creativity Innovation Challenge, Paris, France, pp. 21.

Firdyiwek, Y., \& Scida, E. E. (2014). Reflective course design: An interplay between pedagogy and technology in a language teacher education course. International Journal of ePortfolio, 4(2), 2014.
Gaitán, A. (2012). Understanding students' experiences of e-PDP and the factors that shape their attitudes. International Journal of ePortfolio, 2(1), 29-38.

Gardner, K. M., \& Aleksejuniene, J. (2008) Quantitative and qualitative analysis of student feedback on ePortfolio learning. Journal of Dental Education, 72(11), 1324-1332.

Girish M., Issack S., \& Ravindra B. (2011). Integrating e-portfolios in innovative pedagogical scenarios for enhancement of students' online learning experiences: Learning design specification for an innovative e-portfolio module for the University of Auritius. International Journal of Learning, 18(5), 7-12.

Hsieh, T. C., Chen, S. L., \& Hung, M. C. (2015). Longitudinal test of ePortfolio continuous use: An empirical study on the change of students' beliefs. Behavior \& Information Technology, 34(8), 838-853.

Huang, J., Yang, S., \& Chang, M. (2011). The effect of ePortfolio satisfaction on students' learning motivation and Internet self-efficacy. Journal of Educational Technology Development and Exchange, 4(1), 103-118.

Masari, G. (2013). E-portfolio: A pedagogical tool for professional development of future kindergarten and primary school teachers. E-learning and Software for Education, 2, 406-411.

Ritzhaupt, A., Ndoye, A., \& Parker, M. (2009). In-service teachers and e-portfolios. In I. Gibson et al. (Eds.), Proceedings of Society for Information Technology \& Teacher Education International Conference, Chesapeake, VA: pp. 162167.

Roberts, P. (2014). Design principles for an ePortfolio-based learning environment to enhance reflection in pre-service teachers. Proceedings of World Conference on Educational Media and Technology, 
Chesapeake, VA: pp. 769-774.

Rogers, E. M. (2003). Diffusion of innovations (5th ed.). New York: A Division of Simon \& Schuster.

Shepherd, C. E., \& Bolliger, D. U. (2014). Managing communication and professional development in online graduate programs with electronic portfolios. Online Journal of Distance Learning Administration, 37(2), 1-13.

Silva, K., Larsen, J. E., Park, M., \& Tai, S. J. (2015). Using e-portfolios in language teacher education programs: Reflective practice and professional growth. Proceedings of Society for Information Technology \& Teacher Education International Conference, Chesapeake, VA: pp. 1867-1872.

Smaldino, S. E., Russell, J. D., Heinich, R., \& Molenda, M. (2005). Technology, media, and learning. In S.E. Smaldino, J.D. Russell, R. Heinich, \& M. Molenda (Eds.), Instructional technology and media for learning (pp. 4-23). Upper Saddle River, NJ: Pearson.

Tur, G., \& Urbina, S. (2014). Blogs as ePortfolio platforms in teacher education: Affordances and limitations derived from student teachers' perceptions and performance on their ePortfolios. Digital Education, 26(1), 1-23.

Van Wesel, M. \& Prop. A. (2008). Comparing students' perceptions of paper-based and electronic portfolios. Canadian Journal of Learning and Technology, 34(3).

Wuetherick, B. \& Dickinson, J. (2015). Why ePortfolios? Student perceptions of ePortfolio use in continuing education learning environments. International Journal of ePortfolio, 5(1), 39-53.

Yin, R. K. (2013). Case study research: Design and methods (5th ed.). Thousand Oaks: Sage Publications.

\section{Contact the Author}

\section{Lin Zhong}

The University of Southern Mississippi

Email:lin.zhong@eagles.usm.edu

\section{Taralynn Hartsell}

The University of Southern Mississippi

Email:taralynn.hartsell@usm.edu 